OPEN ACCESS

Edited by:

Walter Araujo Zin,

Universidade Federal do Rio de

Janeiro, Brazil

Reviewed by:

Ramon Farre,

University of Barcelona, Spain

Bela Suki,

Boston University, United States

Sabah Hussain,

Mc Gill University, Canada

*Correspondence:

Marcelo G. de Abreu

mgabreu@ukdd.de

${ }^{\dagger}$ These authors have contributed equally to this work.

Specialty section:

This article was submitted to

Respiratory Physiology,

a section of the journal

Frontiers in Physiology

Received: 23 April 2018

Accepted: 21 June 2018

Published: 12 July 2018

Citation:

Güldner A, Huhle R, Beda A, Kiss T, Bluth T, Rentzsch I, Kerber S,

Carvalho NC, Kasper M, Pelosi P and

de Abreu MG (2018) Periodic

Fluctuation of Tidal Volumes Further

Improves Variable Ventilation in

Experimental Acute Respiratory Distress Syndrome.

Front. Physiol. 9:905.

doi: 10.3389/fphys.2018.00905

\section{Periodic Fluctuation of Tidal Volumes Further Improves Variable Ventilation in Experimental Acute Respiratory Distress Syndrome}

\author{
Andreas Güldner ${ }^{1 \dagger}$, Robert Huhle ${ }^{1 \dagger}$, Alessandro Beda ${ }^{1,2}$, Thomas Kiss ${ }^{1}$, Thomas Bluth ${ }^{1}$, \\ Ines Rentzsch ${ }^{1,3}$, Sarah Kerber ${ }^{1}$, Nadja C. Carvalho ${ }^{1,2}$, Michael Kasper ${ }^{4}$, Paolo Pelosi ${ }^{5}$ and \\ Marcelo G. de Abreu ${ }^{1 *}$ \\ ${ }^{1}$ Department of Anesthesiology and Intensive Care Medicine, Pulmonary Engineering Group, University Hospital Carl Gustav \\ Carus, Technische Universität Dresden, Dresden, Germany, ${ }^{2}$ Departamento de Engenharia Eletrônica, Federal University of \\ Minas Gerais, Belo Horizonte, Brazil, ${ }^{3}$ Department of Orthodontics, Technische Universität Dresden, Dresden, Germany, \\ ${ }^{4}$ Institute of Anatomy, Technische Universität Dresden, Dresden, Germany, ${ }^{5}$ Department of Surgical Sciences and Integrated \\ Diagnostics, IRCCS San Martino IST, University of Genoa, Genoa, Italy
}

In experimental acute respiratory distress syndrome (ARDS), random variation of tidal volumes $\left(V_{T}\right)$ during volume controlled ventilation improves gas exchange and respiratory system mechanics (so-called stochastic resonance hypothesis). It is unknown whether those positive effects may be further enhanced by periodic $V_{T}$ fluctuation at distinct frequencies, also known as deterministic frequency resonance. We hypothesized that the positive effects of variable ventilation on lung function may be further amplified by periodic $V_{T}$ fluctuation at specific frequencies. In anesthetized and mechanically ventilated pigs, severe ARDS was induced by saline lung lavage and injurious $V_{T}$ (double-hit model). Animals were then randomly assigned to $6 \mathrm{~h}$ of protective ventilation with one of four $V_{T}$ patterns: (1) random variation of $V_{T}(\mathrm{WN})$; (2) $\mathrm{P}_{04}$, main $V_{T}$ frequency of $0.13 \mathrm{~Hz}$; (3) $\mathrm{P}_{10}$, main $V_{T}$ frequency of $0.05 \mathrm{~Hz}$; (4) $\mathrm{VCV}$, conventional non-variable volume controlled ventilation. In groups with variable $V_{T}$, the coefficient of variation was identical (30\%). We assessed lung mechanics and gas exchange, and determined lung histology and inflammation. Compared to VCV, WN, $\mathrm{P}_{04}$, and $\mathrm{P}_{10}$ resulted in lower respiratory system elastance $\left(63 \pm 13 \mathrm{~cm} \mathrm{H}_{2} \mathrm{O} / \mathrm{L}\right.$ vs. $50 \pm 14 \mathrm{~cm} \mathrm{H}_{2} \mathrm{O} / \mathrm{L}, 48.4 \pm 21 \mathrm{~cm} \mathrm{H}_{2} \mathrm{O} / \mathrm{L}$, and 45.1 $\pm 5.9 \mathrm{~cm} \mathrm{H} \mathrm{H}_{2} \mathrm{O} / \mathrm{L}$ respectively, $P<0.05$ all), but only $\mathrm{P}_{10}$ improved $\mathrm{PaO}_{2} / \mathrm{F}_{1} \mathrm{O}_{2}$ after $6 \mathrm{~h}$ of ventilation (318 \pm 96 vs. $445 \pm 110 \mathrm{~mm} \mathrm{Hg}, P<0.05)$. Cycle-by-cycle analysis of lung mechanics suggested intertidal recruitment/de-recruitment in $P_{10}$. Lung histologic damage and inflammation did not differ among groups. In this experimental model of severe ARDS, periodic $V_{T}$ fluctuation at a frequency of $0.05 \mathrm{~Hz}$ improved oxygenation during variable ventilation, suggesting that deterministic resonance adds further benefit to variable ventilation.

Keywords: experimental model, acute respiratory distress syndrome, mechanical ventilation, variable ventilation, gas exchange, respiratory mechanics, lung inflammation, lung damage 


\section{INTRODUCTION}

Mechanical ventilation with variable tidal volumes $\left(V_{T}\right)$ has been shown to improve gas exchange as well as lung mechanics (Lefevre et al., 1996; Suki et al., 1998; Mutch et al., 2000, 2005; Funk et al., 2004; Bellardine et al., 2006; Graham et al., 2011a,b) and attenuate ventilator induced lung injury (VILI) (Boker et al., 2002; Spieth et al., 2009b; Thammanomai et al., 2013; de Magalhães et al., 2016; Samary et al., 2016) in different models of the acute respiratory distress syndrome (ARDS). In these studies, artificial as well as biologically variable $V_{T}$ patterns have been investigated.

During variable ventilation, $V_{T}$ patterns are often described using the coefficient of variation (CV), even when probability density distributions are not strictly normal. Early investigations focused on the optimization of $\mathrm{CV}$ to improve lung function (Arold et al., 2002; Spieth et al., 2009a) and attenuate lung injury (Kiss et al., 2016). In oleic acid induced lung injury in porcine, a $C V \geq 40 \%$ was associated with an optimal combination of gas exchange and lung mechanics, while a CV of $30 \%$ attenuated VILI (Kiss et al., 2016).

More recently, different $V_{T}$ probability density distributions were investigated in mice. In lung injury induced by hydrochloric acid, a $V_{T}$ probability density distribution tailored to maximize recruitment allowed better gas exchange and respiratory mechanics with reduced lung inflammation compared to random variable ventilation (Thammanomai et al., 2008, 2013).

Aside from this, advanced $V_{T}$ pattern properties (e.g., power distribution, auto-correlation, complexity) have been only addressed once in a model of oleic acid induced lung injury in pigs comparing biologically and random white noise variable $V_{T}$ patterns (Froehlich et al., 2008). Both patterns yielded similar improvements in gas exchange and lung mechanics arguably because both patterns did not differ relevantly in terms of autocorrelation, given the possible range of values. Except for a study in a numerical model of respiratory mechanics (Ma et al., 2011) the impact of determinism during randomly variable ventilation have not been addressed in experimental models of ARDS yet.

In the present study, we investigated the effects of distinct $V_{T}$ pattern frequencies, so-called deterministic frequency resonance, on gas exchange, lung mechanics, hemodynamics, histology, and

\footnotetext{
Abbreviations: ARDS, Acute respiratory distress syndrome; CPAP, Continuous positive airway pressure ventilation mode; $\mathrm{CV}$, Coefficient of variation in \%, defined as $\mathrm{CV}={ }^{*} 100$ with $\mathrm{V}_{\mathrm{T}, \mathrm{I}}$; $\mathrm{CVP}$, Central venous pressure in $\mathrm{mm} \mathrm{Hg}$; DAD, Diffuse alveolar damage score; $E$, Total respiratory system elastance: $\mathrm{E}=\mathrm{E}_{1}+\mathrm{E}_{2}$. $\mathrm{V}_{\mathrm{T}}$ in $\mathrm{cm} \mathrm{H}_{2} \mathrm{Oml}^{-1} ; \mathrm{E}_{1}$, Volume independend respiratory system elastance in $\mathrm{cm}$ $\mathrm{H}_{2} \mathrm{O} \cdot \mathrm{ml}^{-1} ; \mathrm{E}_{2}$, Volume dependend respiratory system elastance in $\mathrm{cm} \mathrm{H}_{2} \mathrm{O} \cdot \mathrm{ml}^{-2}$; $\% \mathrm{E}_{2}$, Volume dependence index of respiratory system elastance in \%; HR, Heart rate in $\mathrm{min}^{-1}$; MAP, Mean arterial pressure in $\mathrm{mm} \mathrm{Hg}$; MPAP, Mean pulmonary arterial pressure in $\mathrm{mm} \mathrm{Hg} ; \mathrm{P}_{0}$, Minimal airway pressure per respiratory cycle in $\mathrm{cm} \mathrm{H}_{2} \mathrm{O} ; \mathrm{WN}, \mathrm{P}_{04}, \mathrm{P}_{10}$, Pattern of variable ventilation without, every 4 and every 10 resp. cycles recurrence (periodicity); $\mathrm{P}_{\mathrm{aw}}$, mean|plat|max, Minimal, mean, plateau and maximal airway pressure in $\mathrm{cm} \mathrm{H}_{2} \mathrm{O}$; PCWP, Pulmonary capillary wedge pressure in $\mathrm{mm} \mathrm{Hg}$; PEEP, Positive end-expiratory pressure in $\mathrm{cm} \mathrm{H}_{2} \mathrm{O}$; R, Respiratory system resistance in $\mathrm{cm} \mathrm{H}_{2} \mathrm{O} \cdot \mathrm{s} \cdot \mathrm{ml}^{-1}$; R/D, Recruitment / derecruitment: repeated opening and closing of lung regions; RR, Respiratory rate set at the ventilator in $\mathrm{min}^{-1}$; VCV, Conventional volume controlled ventilation; $V_{T}$, Mean inspiratory tidal volume in $\mathrm{ml} \cdot \mathrm{kg}^{-1}$ actual body weight; $V_{T, I}$. Inspiratory tidal volume of the i-th respiratory cycle.
}

inflammation during variable controlled mechanical ventilation in experimental ARDS. We hypothesized that, during volume controlled mechanical ventilation, deterministic frequency resonance through $V_{T}$ fluctuation improves lung function and reduces lung injury during variable ventilation.

\section{METHODS}

The local animal care committee approved the experimental protocol (TVA 24-9168.11-1/2011-22) (Landesdirektion Dresden, Dresden, Saxony, Germany).

\section{Anesthesia and Initial Ventilator Settings}

In total, 40 female pigs with mean body weight of $40.4 \mathrm{~kg}$ (29.9-50.5 kg, German landrace) were investigated. Animals were pre-medicated intramuscularly with $10 \mathrm{mg} / \mathrm{kg}$ ketamine (Ketamin-ratiopharm; Ratiopharm, Ulm, Germany) and 1 $\mathrm{mg} / \mathrm{kg}$ midazolam (Midazolam, Ratiopharm, Ulm, Germany), and had the trachea intubated with a cuffed $8.0-\mathrm{mm}$ ID endotracheal tube. Initially, mechanical ventilation (Evita XL, Dräger Medical, Lübeck, Germany) was performed in volumecontrolled mode with the following settings: fraction of inspired oxygen $\left(\mathrm{FIO}_{2}\right)=1.0, V_{T}=10 \mathrm{~mL} / \mathrm{kg}$, positive end-expiratory pressure (PEEP) $=5 \mathrm{~cm} \mathrm{H}_{2} \mathrm{O}$, inspiratory to expiratory time ratio $(\mathrm{I}: \mathrm{E})=1: 1$ and respiratory rate $(\mathrm{RR})$ to keep $\mathrm{PaCO}_{2}$ in the range of $35-45 \mathrm{~mm} \mathrm{Hg}$.

Anesthesia was maintained by means of continuous intravenous infusion of midazolam $(1-2 \mathrm{mg} / \mathrm{kg} / \mathrm{h})$ and ketamine $(10-20 \mathrm{mg} / \mathrm{kg} / \mathrm{h})$. Muscle paralysis was achieved by continuous administration of atracurium $(1-2 \mathrm{mg} / \mathrm{kg} / \mathrm{h})$, whereas the volume status was maintained with a continuous infusion of Ringer's acetate (RA- Ringer-Acetat-Lösung Bernburg, Serumwerk Bernburg AG, Bernburg, Germany) at $10 \mathrm{~mL} / \mathrm{kg} / \mathrm{h}$. The external jugular vein and internal carotid artery were cannulated with 8.5 Fr. Sheaths. The arterial line was used for continuous blood pressure measurements and blood sampling. A pulmonary artery catheter (Opticath, Abbott, Abbott Park, Chicago, IL, USA) was advanced through the venous sheath into the pulmonary artery for continuous measurement of pulmonary arterial blood pressure, mixed venous blood sampling and cardiac output measurements. During the whole experiments, animals were kept supine.

TABLE 1 | Dynamics of sub-systems and processes related to respiration.

\begin{tabular}{|c|c|c|c|}
\hline Sub-system/Process & $\tau$ in $s$ & Frequency in $\mathrm{Hz}$ & References \\
\hline Lung Recruitment & $1.8 \ldots 10.7$ & $0.09 \ldots 0.60$ & $\begin{array}{l}\text { Neumann et al., 1998; } \\
\text { Markstaller et al., } 2001\end{array}$ \\
\hline Ca2+ mobilization & $9 \ldots 13$ & $0.08 \ldots 0.11$ & Wirtz and Dobbs, 1990 \\
\hline Lung derecruitment & $20 \ldots 26.5$ & $0.04 \ldots 0.05$ & $\begin{array}{l}\text { Haller et al., 1998; } \\
\text { Majumdar et al., } 2012\end{array}$ \\
\hline $\begin{array}{l}\text { Surfactant prod./ } \\
\text { release }\end{array}$ & $19.7 \ldots 94.6$ & $0.01 \ldots 0.05$ & $\begin{array}{l}\text { Bates and Irvin, 2002; } \\
\text { Massa et al., } 2008\end{array}$ \\
\hline HPV & 120.151 & $0.008 \ldots 0.007$ & Sylvester et al., 2012 \\
\hline
\end{tabular}

HPV, Hypoxic pulmonary vasoconstriction. 


\section{Induction of Lung Injury}

Lung injury was induced by saline lung lavage and injurious mechanical ventilation (double-hit model), as described elsewhere (Silva et al., 2013). Briefly, multiple lavages with warmed normal saline solution was performed until $\mathrm{PaO}_{2} / \mathrm{FIO}_{2}$ fell below $200 \mathrm{~mm} \mathrm{Hg}$ and remained stable at this level for $\geq$ $30 \mathrm{~min}$ (1st hit). Following that, ventilator induced lung injury was performed with the following settings: driving pressure of $60 \mathrm{~cm} \mathrm{H}_{2} \mathrm{O}, \mathrm{PEEP}=0 \mathrm{~cm} \mathrm{H}_{2} \mathrm{O}, \mathrm{RR}=10 \mathrm{~min}^{-1}$, for $5 \mathrm{~min}$ (2nd hit). After the 2 nd hit previous ventilator settings at baseline 1 were resumed, resulting in $\mathrm{PaO}_{2} / \mathrm{FIO}_{2}<100 \mathrm{mmHg}$. Lung injury was considered stable, when $\mathrm{PaO}_{2}$ did not increase within $15 \mathrm{~min}$.

\section{Patterns of Tidal Volume Variability}

It was shown in the literature that the positive effects of variable ventilation with random variation of $V_{T}$ depend on the probability distribution in general and more specifically on the coefficient of variation (stochastic resonance). Therefore, in order to delineate potential effects of deterministic frequency resonance and stochastic resonance, $V_{T}$ patterns were constructed with the constraint of identical probability distribution (Suki et al., 1998; Brewster et al., 2005). Deterministic resonance requires a (sub-) system to be stimulated by frequency specific excitation. Potential sub-systems related directly to the respiratory system have dynamic characteristics (Table 1 and Supplementary Material).
Three sequences of $V_{T}$ cycles with distinct variability patterns were constructed. Initially, a random white noise $V_{T}$ sequence with Gaussian distribution was generated using Matlab version R14 (Natick, MA, USA) (WN). The probability density histogram of the original sequence was subdivided in two, respectively in five sections of equal areas under the Gaussian curve. In this way two $V_{T}$ sequences were generated taking one value of each consecutive area under the curve, as shown in Figure 1. Each $V_{T}$ pattern consisted of the exactly same 600 values and thus had identical probability density distribution ( $\mathrm{cmp}$. Supplementary Table 1). At a mean respiratory rate of $30 \mathrm{bpm}$ each pattern had a length of $\sim 20 \mathrm{~min}$. Each pattern was repeated 18 times during the $6 \mathrm{~h}$ of therapy. Mean $V_{T}$ of all patterns was $6 \mathrm{ml} / \mathrm{kg}$ and single cycle $V_{T}$ values ranged from 0.6 to $11.4 \mathrm{ml} / \mathrm{kg}(99.7 \%$ of all values). $95 \%$ of all $V_{T}$ values were in the range of $2.4 \ldots 9.6 \mathrm{ml} / \mathrm{kg}$.

Accordingly, the pattern of the second sequence showed periodic recurrence every four cycles $\left(\mathrm{P}_{04}\right)$. Considering a respiratory frequency of $30 \mathrm{~min}^{-1}$ (the average value used in the present study), this periodicity corresponds to a main frequency of $0.13 \mathrm{~Hz}$, coinciding with the dynamics of lung recruitment and stretch induced calcium mobilization (Wirtz and Dobbs, 1990), whereas the third pattern using periodic recurrence every 10 cycles $\left(\mathrm{P}_{10}\right)$ resulted in a main frequency of $0.05 \mathrm{~Hz}$ (considering a respiratory rate $30 \mathrm{~min}^{-1}$ ) coinciding with dynamics of lung derecruitment and surfactant production and release (Bates and Irvin, 2002; Massa et al., 2008). All three variable $V_{T}$ patterns

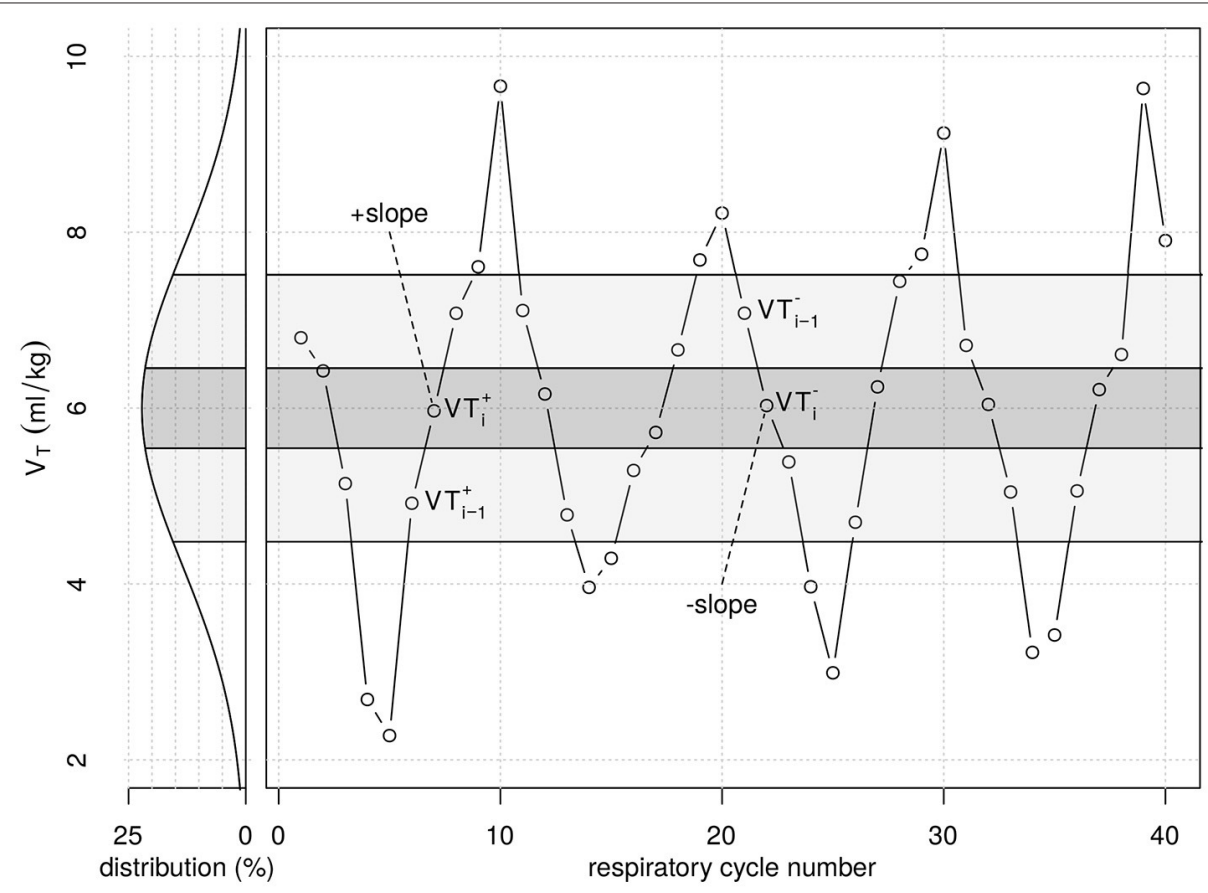

FIGURE 1 | Graphical illustration of part of the tidal volume $\left(V_{T}\right)$ series from period pattern $P_{10}$. Original $V_{T}$ values were randomly generated following a Gaussian distribution (white noise), with respective probability density (left). $V_{T}$ values were then taken from each of the five probability density regions shown (quintiles of the original random $V_{T}$ series) and re-ordered from lowest to highest (+slope) and highest to lowest (-slope) $V_{T}$ values, repetitively. $V_{T}$ i-1 represents $V_{T}$ in the second quintile during +slope, while $V_{T i-1}$ represents $V_{T}$ in the fourth quintile during -slope. $V_{T i+}$ and $V_{T i}$ represent $V_{T}$ in the third quintile during-slope and +slope, respectively, which value is close to the mean of $6 \mathrm{~mL} / \mathrm{kg}$. The period pattern $\mathrm{P}_{04}$ was generated similarly, dividing the probability distribution curve into two density regions only. 
were applied by remote control of the mechanical ventilator (Evita XL, Dräger Medical, Lübeck, Germany), as described by our group (Spieth et al., 2009b).

\section{Protocol for Measurements}

Measurements of gas exchange, hemodynamics, respiratory variables and distribution of ventilation were performed after instrumentation (Baseline 1) and induction of lung injury (Injury). Protective mechanical ventilation was then initiated in volume controlled ventilation mode with the following settings: $V_{T}=6 \mathrm{~mL} / \mathrm{kg}$, PEEP $=12 \mathrm{~cm} \mathrm{H}_{2} \mathrm{O}, \mathrm{I}: \mathrm{E}=1: 1, \mathrm{RR} \leq$ $35 \mathrm{~min}^{-1}$ titrated to maintain $\mathrm{pHa}>7.30$ and $\mathrm{FIO}_{2}=0.7$. After a stabilization period of $30 \mathrm{~min}$, measurements were repeated (Baseline 2). Following that, animals were randomly assigned to one of the following mechanical ventilation: (1) non-variable $V_{T}(\mathrm{VCV})$; (2) variable $V_{T}$ with white noise pattern $(\mathrm{WN})$; (3) variable periodic $V_{T}$ pattern with a periodic recurrence of 4 respiratory cycles $\left(\mathrm{P}_{04}\right)$; and $(4)$ variable periodic $V_{T}$ pattern


FIGURE 2 | Tracing records of airway flow, volume, and airway pressure $\left(P_{a w}\right)$ in one representative animal per group. (A) Conventional volume controlled ventilation (VCV); (B) variable ventilation with Gaussian white noise pattern (WN); (C) variable ventilation with periodicity of 4 cycles ( $\left.\mathrm{P}_{04}\right)$ and (D) variable ventilation with periodicity of 10 cycles $\left(P_{10}\right)$. 
with a periodic recurrence of 10 respiratory cycles $\left(\mathrm{P}_{10}\right)$. Other ventilator settings were kept constant in all groups, and animals ventilated during a period of $6 \mathrm{~h}$, with measurements performed every hour (Times 1-6).

\section{Respiratory System Mechanics}

Airflow $(V)$ was measured by the internal sensor of the mechanical ventilator. Airway pressure $\left(P_{a w}\right)$ was monitored by a pressure transducer (163PC01D48-PCB, Sensortechnics $\mathrm{GmbH}$, Germany) placed at proximal side of the tracheal tube. Signals were acquired at sample frequency of $500 \mathrm{~Hz}$ using a data acquisition card (NI USB-6210, National Instruments, Austin, TX, USA) connected to a PC, and synchronized off-line according to the maximal co-variance criterion.

Respiratory system resistance $(R)$ and elastance $\left(E=E_{1}+E_{2} \cdot V_{T}\right)$ were determined by least-means-squares (LMS) fitting of the respiratory signals to the equation of motion:

$$
P_{a w}(t)=E_{1} \cdot V(t)+E_{2} \cdot V^{2}(t)+R \cdot \dot{V}(t)+P_{0}
$$

where $E_{1}$ is the volume-independent and $E_{2}$ the volumedependent $E$, and $P_{0}$ the end-expiratory airway pressure. The contribution of volume-dependent $E$ to total $E\left(\% E_{2}\right)$ was calculated as described elsewhere (Kano et al., 1994).

The amount of inter-tidal recruitment-/derecruitment (R/D) was estimated from cycle-to-cycle differences in $E$. A given respiratory cycle was classified as -slope or + slope if its $V_{T}$ was within a range of $6 \mathrm{~mL} / \mathrm{kg} \pm 0.045 \mathrm{~mL} / \mathrm{kg}\left(V_{T, i}^{+}\right.$and $\left.V_{T, i}^{-}\right)$and its preceding cycle had a $V_{T}$ value within $7-9 \mathrm{~mL} / \mathrm{kg}\left(V_{T, i-1}^{-}\right)$ or 3-5 mL/kg $\left(V_{T, i-1}^{+}\right)$, respectively (Figure 1$)$. The difference in $E$ measured between - slope and + slope cycles was calculated as $\Delta E=E_{- \text {slope }}-E_{+ \text {slope }}$. Negative $\Delta E$-values were classified as inter-tidal recruitment, whereas positive $\Delta E$-values were indicative of inter-tidal derecruitment.

\section{Distribution of Regional Ventilation}

Regional ventilation distribution was assessed by electrical impedance tomography (EIT). Detailed methods and analysis of EIT are described in detail in Supplementary Material. Briefly, a 16 electrode belt was placed at mid chest circumference and connected to the EIT Evolution Kit 2 (Draeger Medical AG, Germany). The distribution of relative ventilation in ventral, central and dorsal regions was quantified, and the homogeneity, contrast and energy of tidal images were determined.

\section{Hemodynamics and Gas Exchange}

Mean arterial and pulmonary arterial pressures were measured continuously (MAP and MPAP, respectively). Cardiac output (CO) was measured with a pulmonary artery catheter by thermodilution, and oxygen derived variables, including venous admixture, were obtained using standard formulae.

Arterial and mixed venous blood samples were analyzed for respiratory gases and $\mathrm{pH}$ using an ABL 505 blood gas analyzer (Radiometer, Copenhagen, Denmark), and for oxygen saturation and hemoglobin concentration with an OSM3 Hemoximeter (Radiometer) calibrated for swine blood. Gas tension measurements were performed at $37^{\circ} \mathrm{C}$ and corrected for body temperature measured by the pulmonary arterial catheter. To compensate for the influence of varying $\mathrm{V}_{\mathrm{T}}$ on blood gases, blood samples were drawn along four to five respiratory cycles, $8-10$ s respectively. During $P_{10}$, two subsequent blood samples were taken and values averaged.

\section{Post Mortem Processing}

At the end of the observation period, heparin was administered (1,000 IU/kg i.v.) (Ratiopharm, Ulm, Germany) and animals were killed by i.v. injection of $2 \mathrm{~g}$ thiopental (Inresa, Arzneimittel $\mathrm{GmbH}$, Freiburg, Germany) followed by $50 \mathrm{~mL} \mathrm{KCl} 1 \mathrm{M}$
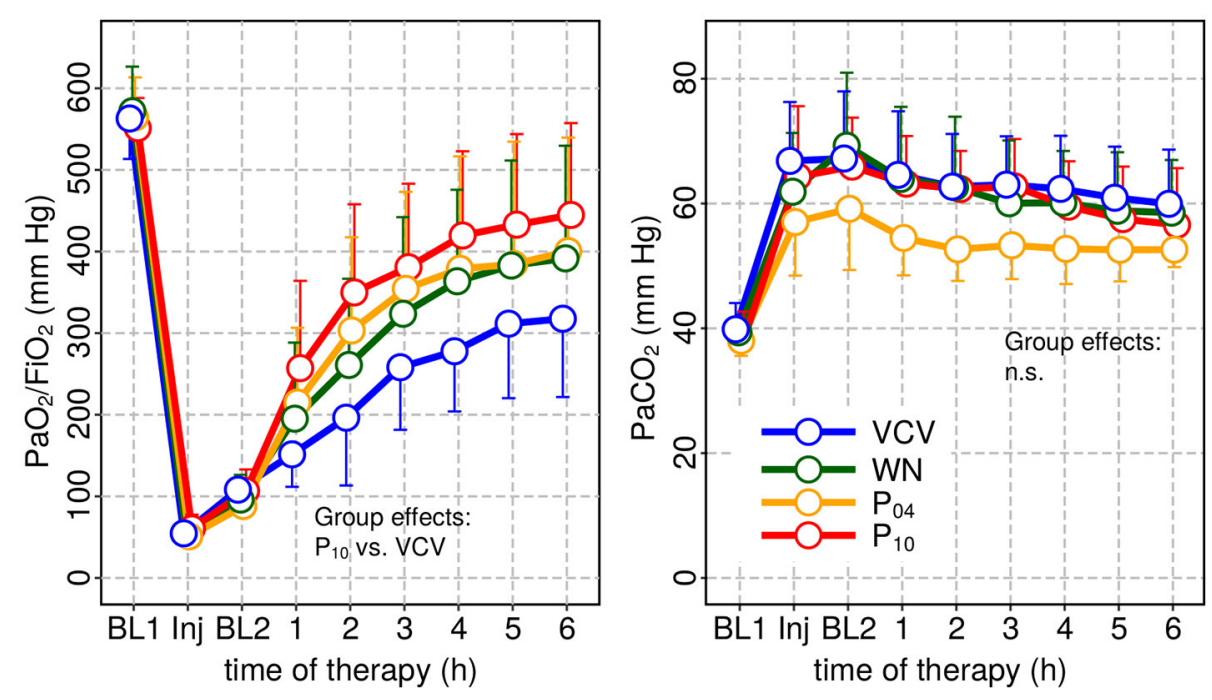

FIGURE 3 | Arterial oxygenation $\left(\mathrm{PaO}_{2} / \mathrm{F}_{1} \mathrm{O}_{2}\right)$ and arterial carbon-dioxide partial pressure $\mathrm{PaCO}_{2}$ at baseline $1(\mathrm{BL} 1)$, injury and baseline 2 (BL2) and during subsequent therapy. $\mathrm{PaO}_{2}$ was significantly increased only for $\mathrm{P}_{10}$ compared to VCV. 
(Serumwerk Bernburg, Germany). Lungs were removed maintaining continuous positive airway pressure $(C P A P)$ equal to the PEEP level during the observation period. Samples from gravitationally dependent (dorsal) and non-dependent (ventral) areas of the right lower lung lobe were snap-frozen in liquid nitrogen and stored at $-80^{\circ} \mathrm{C}$ until further analysis. For tissue histologic evaluation, the left lower lung lobe was perfused with $4 \%$ buffered formaldehyde solution, while CPAP equivalent to the PEEP level during the observation period was maintained at the airway. Lung tissue samples of $\sim 8 \mathrm{~cm}^{3}$ were taken from ventral and dorsal zones of the left lower lung lobe.

\section{Markers of Inflammation and Mechanical Cell Stress}

Total RNA from lung tissue was isolated with TRI reagent (Sigma-Aldrich GmbH, Deisenhof, Germany) according to the manufacturer's protocol, followed by purification with NucleoSpin RNA II columns (Macherey\&Nagel, Düren, Germany). The complementary deoxyribonucleic acid was synthesized with the Revert AidTM H Minus First Strand Synthesis Kit (MBI Fermentas, St. Leon Roth, Germany) from 1 $\mu \mathrm{g}$ total RNA according to instructions of the fabricant. Using cyclophilin A and B2-microglobulin as housekeeping genes, the mRNA expression of the inflammatory mediators tumor necrosis factor $\alpha$ (TNF- $\alpha$ ), interleukin 6 and 8 (IL-6, IL-8), amphiregulin and tenascin-c were quantified with quantitative real-time polymerase chain reaction (Maxima SYBR Green qPCR MasterMix, Fermentas, St. Leon Roth, Germany) in the iCycler MyiQ2 real time polymerase chain reaction system (BioRad, Munich, Germany). The total protein content in lung tissue was measured using the BioRad Protein Assay (BioRad, Munich, Germany). Protein levels of TNF- $\alpha$, IL-6, and IL- 8 were measured in lung tissue using commercial ELISA kits (R\&D Systems, Wiesbaden, Germany) according to the manufacturer's instructions.

\section{Histological Damage}

Following perfusion fixation and immersion in $4 \%$ buffered formaldehyde solution for 7 days, tissue samples were embedded

TABLE 2 | Hemodynamics and oxygen derived parameters.

\begin{tabular}{|c|c|c|c|c|c|c|c|c|c|c|}
\hline Variable Group & BL1 & Injury & BL2 & Time 1 & Time 2 & Time 3 & Time 4 & Time 5 & Time 6 & Group effect \\
\hline \multicolumn{11}{|l|}{$\dot{Q}_{\mathrm{VA}} / \mathbf{Q}_{\mathrm{t}}(\%)$} \\
\hline VCV & $11.8 \pm 5.2$ & $58.1 \pm 09$ & $44 \pm 22$ & $27.9 \pm 15$ & $20.1 \pm 08$ & $18 \pm 7.5$ & $25 \pm 25$ & $16 \pm 5.7$ & $15 \pm 5.4$ & \\
\hline WN & $10.8 \pm 5.3$ & $59.8 \pm 16$ & $45 \pm 16$ & $23.5 \pm 12$ & $24.5 \pm 20$ & $15 \pm 5.7$ & $13 \pm 4.0$ & $12 \pm 4.7$ & $12 \pm 6.1$ & \\
\hline$P_{04}$ & $11.9 \pm 4.6$ & $57.7 \pm 13$ & $44 \pm 12$ & $19.6 \pm 6.2$ & $14.5 \pm 4.5$ & $12 \pm 3.5$ & $12 \pm 5.5$ & $12 \pm 6.1$ & $12 \pm 6.3$ & \\
\hline$P_{10}$ & $13.0 \pm 4.4$ & $51.8 \pm 15$ & $37 \pm 11$ & $16.8 \pm 3.6$ & $14.0 \pm 3.3$ & $12 \pm 2.7$ & $11 \pm 3.1$ & $10 \pm 5.0$ & $09 \pm 4.4$ & \\
\hline \multicolumn{11}{|l|}{ CO (L/min) } \\
\hline VCV & $4.6 \pm 1$ & $5.4 \pm 2.1$ & $4.9 \pm 2.1$ & $4.2 \pm 1.4$ & $3.7 \pm 0.9$ & $3.5 \pm 0.7$ & $3.6 \pm 0.8$ & $3.6 \pm 0.8$ & $3.5 \pm 0.8$ & \\
\hline WN & $5.0 \pm 1.0$ & $6.1 \pm 1.6$ & $5.1 \pm 1.4$ & $4.3 \pm 0.7$ & $3.9 \pm 0.6$ & $3.8 \pm 0.6$ & $3.9 \pm 0.6$ & $3.9 \pm 0.5$ & $3.9 \pm 0.6$ & \\
\hline $\mathrm{P}_{04}$ & $5.3 \pm 1.2$ & $5.8 \pm 1.7$ & $5.3 \pm 1.1$ & $4.1 \pm 1.1$ & $3.7 \pm 0.8$ & $3.5 \pm 0.6$ & $3.5 \pm 0.7$ & $3.6 \pm 0.8$ & $3.5 \pm 0.8$ & \\
\hline$P_{10}$ & $4.7 \pm 1.1$ & $4.6 \pm 0.7$ & $4.4 \pm 0.9$ & $3.8 \pm 0.8$ & $3.6 \pm 0.8$ & $3.7 \pm 0.7$ & $3.4 \pm 0.8$ & $3.4 \pm 0.8$ & $3.4 \pm 0.9$ & \\
\hline \multicolumn{11}{|l|}{$\mathrm{HR}\left(\min ^{-1}\right)$} \\
\hline VCV & $97.5 \pm 14$ & $101 \pm 14$ & $96.0 \pm 15$ & $88.0 \pm 12$ & $83.2 \pm 9$ & $82.4 \pm 10$ & $79.1 \pm 11$ & $78.0 \pm 10$ & $79.5 \pm 11.0$ & \\
\hline WN & $94.1 \pm 12$ & $103 \pm 15$ & $93.4 \pm 12$ & $83.2 \pm 12$ & $82.1 \pm 12$ & $78.8 \pm 10$ & $77.0 \pm 8$ & $76.0 \pm 6.6$ & $73.2 \pm 7.5$ & \\
\hline $\mathrm{P}_{04}$ & $92.8 \pm 7.6$ & $105 \pm 19$ & $98.1 \pm 9.9$ & $83.5 \pm 7.8$ & $80.7 \pm 5.5$ & $78.3 \pm 3.4$ & $75.7 \pm 4.8$ & $74.5 \pm 5.9$ & $72.2 \pm 6.7$ & \\
\hline$P_{10}$ & $101 \pm 12$ & $95.5 \pm 15$ & $92.0 \pm 13$ & $85.3 \pm 10$ & $83.6 \pm 13$ & $80.6 \pm 14$ & $77.3 \pm 16$ & $75.9 \pm 16$ & $76.8 \pm 17$ & \\
\hline \multicolumn{11}{|l|}{ MAP (mm Hg) } \\
\hline VCV & $72 \pm 11$ & $89 \pm 10$ & $89 \pm 14$ & $90 \pm 12$ & $88 \pm 10$ & $86 \pm 09$ & $85 \pm 09$ & $82 \pm 08$ & $80 \pm 09$ & \\
\hline WN & $76 \pm 09$ & $89 \pm 19$ & $88 \pm 11$ & $87 \pm 08$ & $93 \pm 11$ & $87 \pm 12$ & $85 \pm 12$ & $81 \pm 12$ & $79 \pm 09$ & \\
\hline$P_{04}$ & $74 \pm 13$ & $92 \pm 12$ & $92 \pm 11$ & $91 \pm 11$ & $88 \pm 10$ & $88 \pm 07$ & $85 \pm 10$ & $83 \pm 09$ & $79 \pm 07$ & \\
\hline$P_{10}$ & $83 \pm 13$ & $94 \pm 13$ & $91 \pm 13$ & $89 \pm 11$ & $87 \pm 09$ & $86 \pm 09$ & $82 \pm 10$ & $79 \pm 09$ & $80 \pm 13$ & \\
\hline \multicolumn{11}{|l|}{ MPAP (mm Hg) } \\
\hline VCV & $16.7 \pm 1.6$ & $32 \pm 4.5 .0$ & $30.4 \pm 3.7$ & $29.2 \pm 4.5$ & $28.9 \pm 4.1$ & $31.0 \pm 5.4$ & $27.4 \pm 4.3$ & $27.0 \pm 3.8$ & $25.1 \pm 4.0$ & \\
\hline WN & $22.0 \pm 19.0$ & $33.9 \pm 5.0$ & $30.7 \pm 5.5$ & $28.3 \pm 4.3$ & $27.9 \pm 3.7$ & $28.1 \pm 2.9$ & $28.1 \pm 2.6$ & $27.0 \pm 2.7$ & $26.4 \pm 2.7$ & \\
\hline $\mathrm{P}_{04}$ & $17.4 \pm 4.6$ & $32.2 \pm 5.9$ & $31.7 \pm 4.9$ & $26.7 \pm 4.0$ & $27.2 \pm 3.9$ & $27.4 \pm 4.2$ & $27.3 \pm 4.6$ & $27.2 \pm 4.2$ & $26.3 \pm 3.8$ & \\
\hline$P_{10}$ & $19.3 \pm 3.3$ & $33.6 \pm 3.5$ & $30.3 \pm 4.3$ & $27.6 \pm 4.7$ & $27.1 \pm 5.2$ & $27.0 \pm 4.8$ & $25.1 \pm 4.5$ & $24.3 \pm 4.8$ & $25.0 \pm 4.5$ & \\
\hline
\end{tabular}

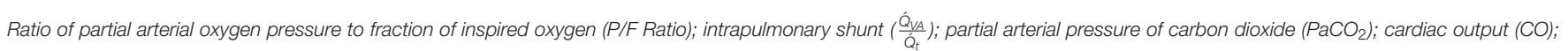

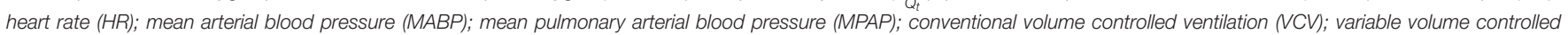

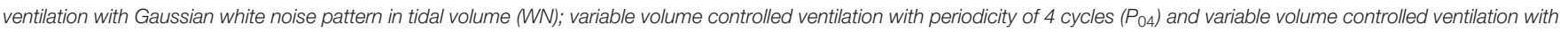

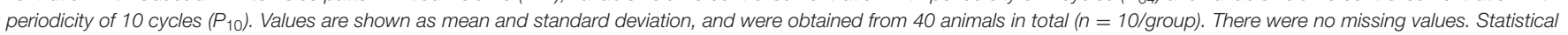

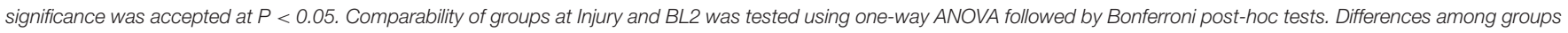
(group main effect) were tested with general linear model statistics using values at BL2 as covariate and adjusted for repeated measurements according to the Sidak procedure. 


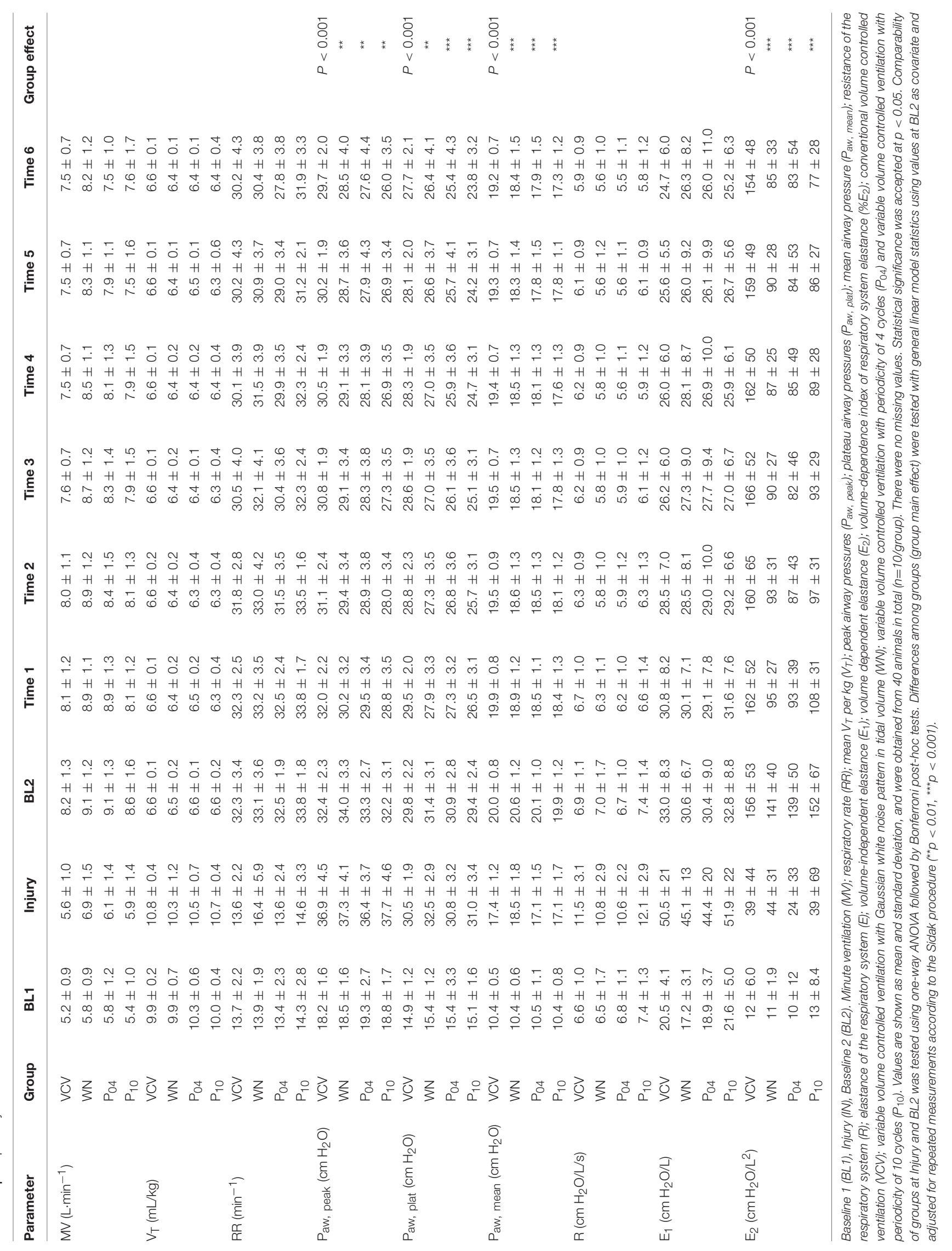


in paraffin, cut in slices of $5 \mu \mathrm{m}$ thickness and stained with hematoxylin-eosin for further analysis. Photomicrographs at magnifications of x25, x100 and x400 were taken from four non-overlapping fields of view per section using a light microscope. Diffuse alveolar damage $(D A D)$ was quantified by one of the authors (MK), who is an expert anatomist and was blinded to the therapy groups, using a weighted scoring system, as described elsewhere (Spieth et al., 2007). Briefly, values from 0 to 5 were used to represent the severity of seven features of $D A D$, i.e. alveolar edema, interstitial edema, hemorrhage, inflammatory infiltration, epithelial destruction, micro atelectasis and over distension, with 0 standing for no effect and 5 for maximum severity. Additionally, the extent of each feature characteristic per field of view was determined with values of 0 to 5 , with 0 standing for no appearance and 5 for complete involvement. The cumulated DAD Score was calculated as the sum of a product of severity and extent of all features, resulting in values within the range from 0 to 175 .

\section{Statistical Analysis}

The sample size calculations for testing the primary hypothesis (periodic $V_{T}$ variation during variable ventilation improves $\mathrm{PaO}_{2} / \mathrm{FIO}_{2}$ ) was based on effects obtained from pilot studies. Accordingly, a sample size of 10 animals would provide appropriate power $(1-\beta=0.80)$ to identify a significant $(\alpha=0.05)$ mean difference of at least $40 \pm 60 \mathrm{mmHg}$, taking two-tailed tests and multiple comparisons $(n=6)$ into account $\left(\alpha^{*}=0.0083, \alpha^{*}\right.$ Bonferroni adjusted).

Data are presented as mean \pm standard deviation, unless stated otherwise. For lung function variables, group differences at Baseline 1, Injury and Baseline 2 were assessed using one-way ANOVA followed by pairwise $T$-test with $p$-value adjustment according to Bonferroni. Differences among groups were tested using two factorial repeated measures ANCOVA with between factor $\mathrm{V}_{\mathrm{T}}$-pattern, within factor time and covariate of the respective parameter at Baseline 2. Posthoc analysis and adjustment for multiple comparisons were performed according to Sidak's procedure. Lung histology, gene expression of pro-inflammatory markers as well as their protein levels in lung tissue were assessed using KruskalWallis test followed by pairwise Mann-Whitney $U$ test with adjustment for multiple comparisons according to BonferroniHolm procedure. Correlation analysis was performed using linear least mean squares modeling. A $p$-value of $\mathrm{P} \leq 0.05$ was considered statistically significant. Statistical analyses was performed using $\mathrm{R}$ Statistical programming language ( $\mathrm{R}$ Core Team, 2016).

\section{RESULTS}

Bodyweight $(38.2 \pm 5.0,42.1 \pm 3.5,42.4 \pm 5.7$, and $38.7 \pm 6.9 \mathrm{~kg}$ in VCV, WN, $\mathrm{P}_{04}$ and $\mathrm{P}_{10}$, respectively) and number of lavages (11, 5-17; 10, 8-13; 10, 4-16, and 12, 5-19; median, min-max for VCV, WN, $\mathrm{P}_{04}$, and $\mathrm{P}_{10}$, respectively) did not differ among groups. Sample signal tracings at the start of therapy for each $V_{T}$ pattern group are depicted in Figure 2.

Hemodynamics and gas exchange variables also did not differ among groups, except to $\mathrm{PaO}_{2} / \mathrm{FIO}_{2}$, which was higher in $\mathrm{P}_{10}$ compared to VCV (Figure 3 and Table 2).

Peak airway pressure $P_{a w \text {,peak }}$, plateau airway pressure $P_{a w \text {,plat }}$ and mean airway pressure $P_{a w, m e a n}$ were significantly reduced in $\mathrm{WN}, \mathrm{P}_{04}$ and $\mathrm{P}_{10}$ compared to VCV. E, $E_{2}$, and $\% E_{2}$ were reduced in $\mathrm{WN}, \mathrm{P}_{04}$ and $\mathrm{P}_{10}$ compared to $\mathrm{VCV}$, whereas $R$ did not differ among groups (Table 3 and Figure 4). In VCV, WN and $\mathrm{P}_{04}$, but
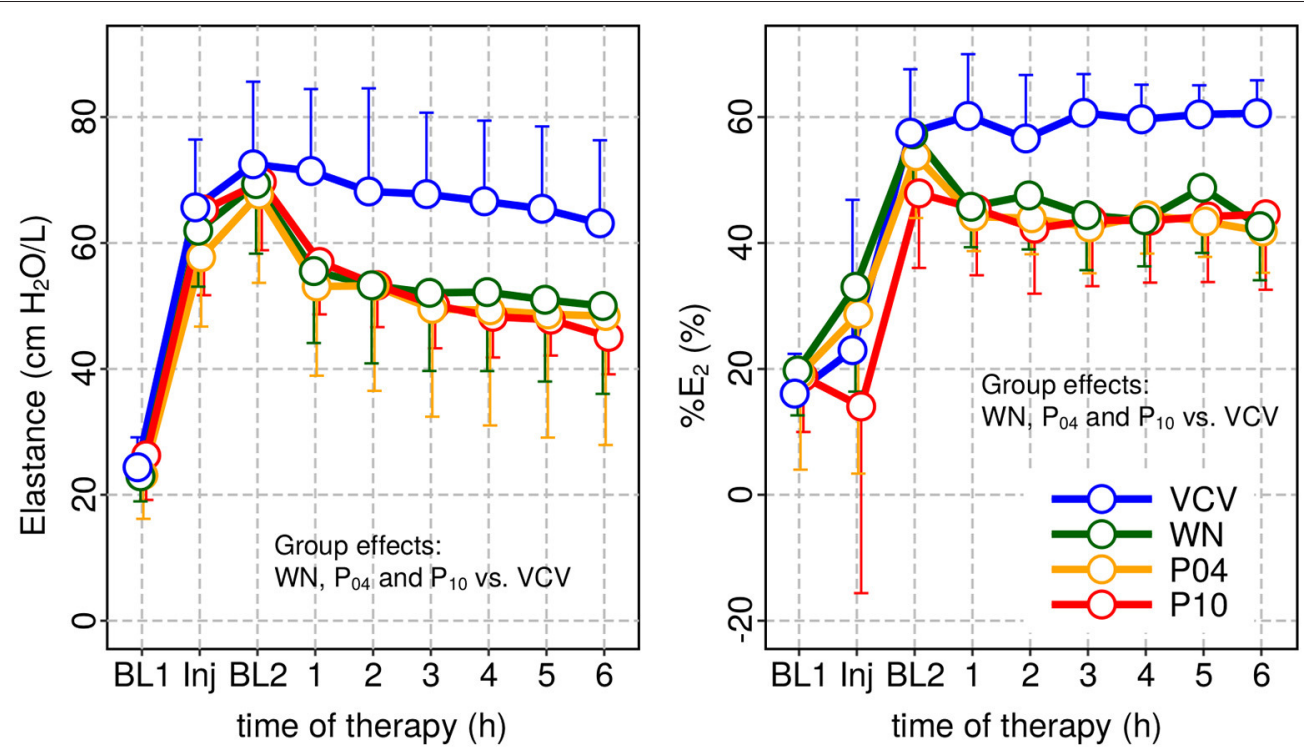

FIGURE 4 | Dynamic respiratory system elastance $(E)$ and relative volume dependence of $E$ (\% $E_{2}$ ) at baseline 1 (BL1), injury and baseline 2 and during subsequent therapy period. In all patterns of variable ventilation $E$ and $\% E_{2}$ were significantly reduced compared to VCV. 
not $\mathrm{P}_{10}$, correlation analyses revealed that $\mathrm{PaO}_{2} / \mathrm{FIO}_{2}$ decreased proportionally to $E$ (Figure 5).

Compared to WN, $\Delta E$ was significantly higher within the $\mathrm{P}_{10}$ pattern, although the tidal volume of the respective preceding cycle $\Delta V_{T, i-1}$ was lowest in the $\mathrm{P}_{10}$ group (Figure 6).

The distribution of regional ventilation did not differ significantly among groups. Analysis of tidal EIT images showed that homogeneity and energy increased, whereas contrast decreased during variable ventilation compared to VCV, irrespective of the $V_{T}$ pattern (see Supplementary Material).

DAD Score (Table 4 and Figure 7), gene expression of markers of inflammation and cell mechanical stress (Table 5), and protein content of pro-inflammatory markers in lung tissue (Table 6), did not differ significantly among groups.

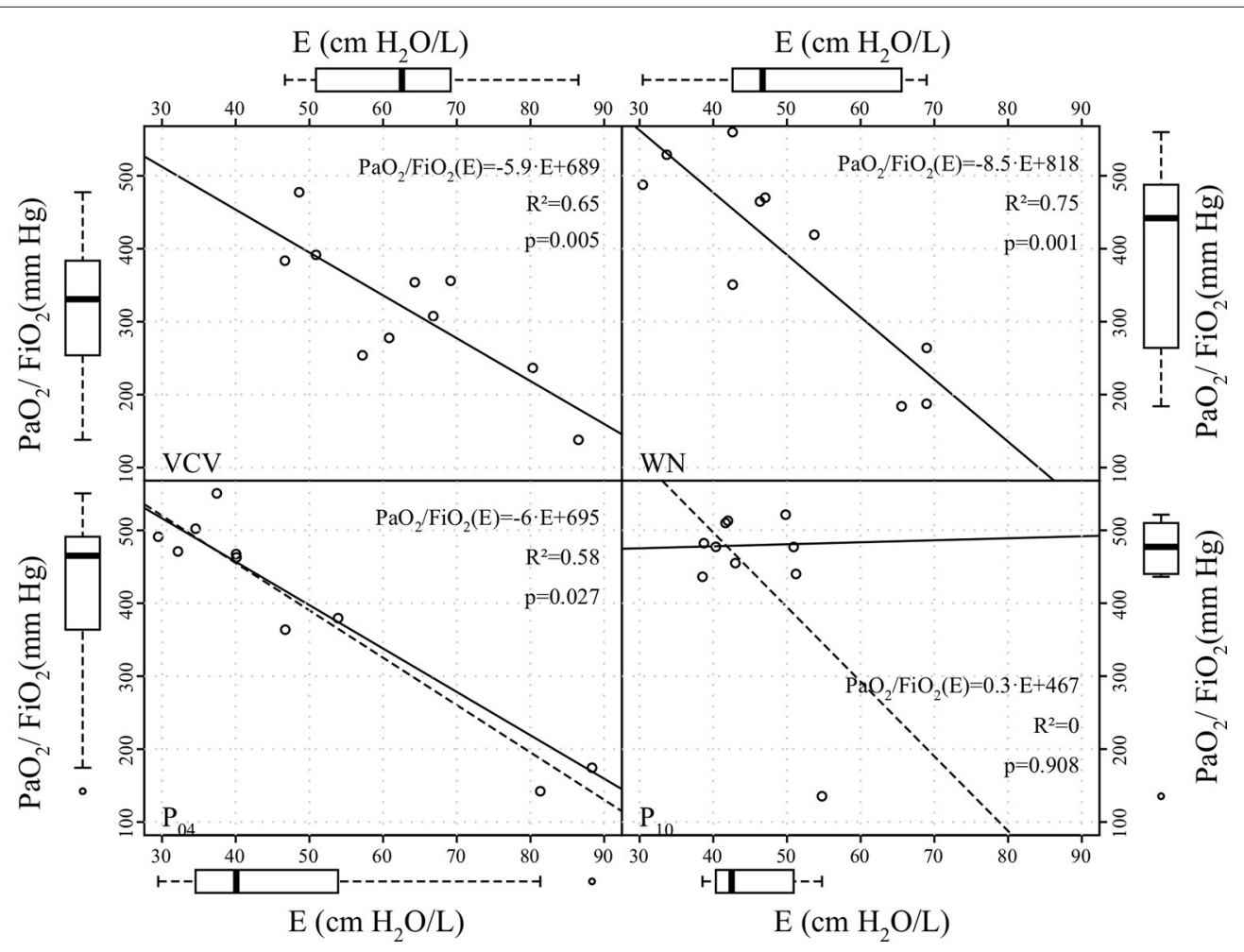

FIGURE 5 | Correlation between arterial partial oxygen pressure to inspiratory oxygen fraction ratio $\left(\mathrm{PaO}_{2} / \mathrm{FiO}_{2}\right)$ and dynamic respiratory system elastance $(E)$ at end of the therapy period. Straight continuous and dashed lines represent linear regression lines without and with outliers, respectively; the coefficients of determination $\left(R^{2}\right)$ were calculated excluding outliers.
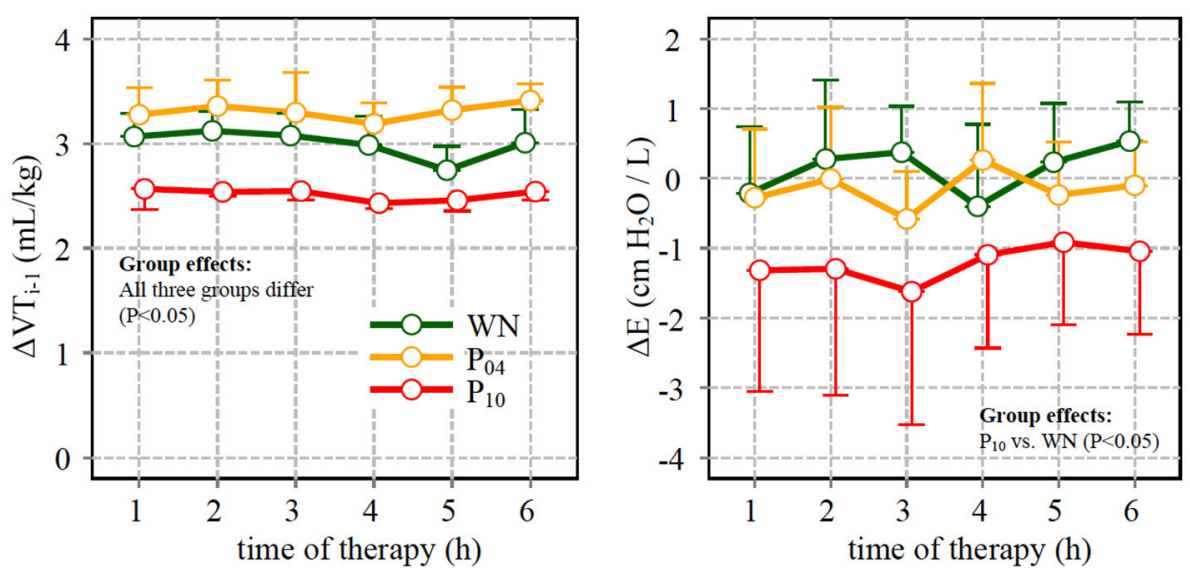

FIGURE 6 | Left: difference between tidal volume $\left(V_{T}\right)$ in the descending limb of a given cycle and in the ascending limb of the preceding cycle $\left(\Delta V_{T}\right.$, i-1) (see also text and Figure 1); Right: difference of dynamic respiratory system elastance ( $\Delta \mathrm{E})$ calculated for cycles with $V_{T}$ value close to the mean (6 mL/kg) in the descending and in the ascending slopes $\left(V_{T i}\right.$ - and $V_{T i}$, respectively) of the respective pattern. 
TABLE 4 | Diffuse alveolar damage.

\begin{tabular}{|c|c|c|c|c|c|}
\hline Feature & group & $\begin{array}{l}\text { Ventral } \\
\text { region }\end{array}$ & $\begin{array}{l}\text { group } \\
\text { effect }\end{array}$ & $\begin{array}{l}\text { Dorsal } \\
\text { region }\end{array}$ & $\begin{array}{l}\text { Group } \\
\text { effect }\end{array}$ \\
\hline \multirow{4}{*}{$\begin{array}{l}\text { Alveolar } \\
\text { edema }\end{array}$} & VCV & $2[0-4]$ & n.s. & $1[0-2]$ & n.s. \\
\hline & WN & $4[1-6]$ & & $1[0-4]$ & \\
\hline & $P_{04}$ & $1[0-8]$ & & $2[0-4]$ & \\
\hline & $P_{10}$ & $2[0-6]$ & & $1[1-3]$ & \\
\hline \multirow{4}{*}{$\begin{array}{l}\text { Intersitial } \\
\text { edema }\end{array}$} & VCV & $1[1-4]$ & n.s. & $1[0-4]$ & n.s. \\
\hline & WN & $2[1-4]$ & & $1[1-3]$ & \\
\hline & $\mathrm{P}_{04}$ & $1[1-4]$ & & $1[1-2]$ & \\
\hline & $P_{10}$ & $2[1-4]$ & & $1[1-4]$ & \\
\hline \multirow[t]{4}{*}{ Hemorrhage } & VCV & $1[0-3]$ & n.s. & $1[0-1]$ & n.s. \\
\hline & WN & $2[1-4]$ & & $1[0-2]$ & \\
\hline & $\mathrm{P}_{04}$ & $1[0-4]$ & & $2[0-3]$ & \\
\hline & $P_{10}$ & $2[0-6]$ & & $1[0-3]$ & \\
\hline \multirow{4}{*}{$\begin{array}{l}\text { Inflammatory } \\
\text { infiltration }\end{array}$} & VCV & $8[3-12]$ & n.s. & $3[1-6]$ & n.s. \\
\hline & WN & $12[5-15]$ & & $3[2-6]$ & \\
\hline & $\mathrm{P}_{04}$ & $6[2-12]$ & & $5[2-8]$ & \\
\hline & $P_{10}$ & $8[1-12]$ & & $3[1-8]$ & \\
\hline \multirow{4}{*}{$\begin{array}{l}\text { Epithelial } \\
\text { destruction }\end{array}$} & VCV & $4[1-4]$ & n.s. & $1[0-4]$ & n.s. \\
\hline & WN & $3[1-6]$ & & $1[1-6]$ & \\
\hline & $\mathrm{P}_{04}$ & $1[0-6]$ & & $2[1-9]$ & \\
\hline & $P_{10}$ & $1[1-8]$ & & $4[1-9]$ & \\
\hline \multirow[t]{4}{*}{ Microatelectasis } & VCV & $4[1-4]$ & n.s. & $1[1-4]$ & n.s. \\
\hline & WN & $2[1-4]$ & & $1[1-2]$ & \\
\hline & $P_{04}$ & $2[1-4]$ & & $2[1-4]$ & \\
\hline & $P_{10}$ & $2[1-4\}$ & & $1[1-2]$ & \\
\hline \multirow[t]{4}{*}{ Overdistension } & VCV & $3[1-6]$ & n.s. & $1[0-3]$ & n.s. \\
\hline & WN & $4[1-8]$ & & $1[0-2]$ & \\
\hline & $\mathrm{P}_{04}$ & $5[0-8]$ & & $2[0-3]$ & \\
\hline & $P_{10}$ & $6[4-7]$ & & $1[0-3]$ & \\
\hline \multirow{4}{*}{$\begin{array}{l}\text { Cumulative } \\
\text { score }\end{array}$} & VCV & 26[13-33] & n.s. & $12[3-20]$ & n.s. \\
\hline & WN & $33[18-43]$ & & $13[7-17]$ & \\
\hline & $\mathrm{P}_{04}$ & $21[5-48]$ & & $18[8-27]$ & \\
\hline & $P_{10}$ & $26[9-45]$ & & $14[6-25]$ & \\
\hline
\end{tabular}

Diffuse alveolar damage in ventral and dorsal lung regions. Conventional volume controlled ventilation (VCV); variable volume controlled ventilation with Gaussian white noise pattern $(W N)$; variable volume controlled ventilation with periodicity of 4 cycles $\left(P_{04}\right)$ and variable volume controlled ventilation with periodicity of 10 cycles $\left(P_{10}\right)$. Values are shown as median and interquartile range, and were obtained from 40 animals in total ( $n=10 /$ group). There were no missing values. Differences among groups were tested with Kruskal-Wallis test followed by Mann-Whitney U-test and Bonferroni-Holm adjustments for pairwise comparisons. n.s (non-significant at $P<0.05)$.

\section{DISCUSSION}

The main finding of this study was that, in an experimental model of severe ARDS in pigs, periodic $V_{T}$ fluctuation at a frequency of $0.05 \mathrm{~Hz}$ enhanced oxygenation and increased inter-tidal R/D during variable ventilation.
To our knowledge, this is the first study comparing different types of variable ventilation with periodic $\mathrm{V}_{\mathrm{T}}$ fluctuation in a large animal model of severe ARDS. Three tidal volume patterns with distinct amplitude-frequency spectra were compared to conventional controlled mechanical ventilation. While $\mathrm{WN}$ has, by definition, a constant, frequency independent spectrum amplitude, there were distinct peaks in the spectra of the pattern $\mathrm{P}_{04}$ and $\mathrm{P}_{10}$ at one quarter $\left(\mathrm{f}_{\mathrm{P} 04}=0.13 \mathrm{~Hz}\right)$ and one tenth $\left(f_{\mathrm{P} 10}=0.05 \mathrm{~Hz}\right)$ of the average respiratory frequency $(0.5 \mathrm{~Hz})$, respectively. In mice with hydrochloric acid injured lungs, a decaying probability density distribution tailored toward high $V_{T}$ values outperformed the original variable ventilation pattern based on a Gaussian distribution with respect to lung mechanics and gas exchange (Thammanomai et al., 2008, 2013), likely due to lung recruitment (Graham et al., 2011b). Different from these previous studies, we selected $V_{T}$ patterns with identical probability density distributions.

Our data showed that oxygenation was significantly improved only in $\mathrm{P}_{10}$, when $V_{T}$ fluctuated at a frequency of $0.05 \mathrm{~Hz}$. In contrast, $E$ was significantly reduced in all variable ventilation groups compared to VCV, a finding that is in line with previous studies (Arold et al., 2002; Funk et al., 2004; Spieth et al., 2009b). The correlation analysis revealed that, with increasing $V_{T}$ fluctuation period, variations in $\mathrm{PaO}_{2} / \mathrm{FiO}_{2}$ were less well explained by variations in $E$. There are two possible explanations for this observation: (1) with increasing period lung recruitment was more stable over multiple respiratory cycles, for example due to enhanced surfactant production/release; (2) periodic $V_{T}$ fluctuation redistributed perfusion more effectively, improving ventilation/perfusion matching.

To investigate whether inter-tidal R/D cycling occurs along with periodic $V_{T}$ variation we performed the cycle-type analysis selecting respiratory cycles with mean $V_{T}$ whose preceding cycle had a higher or lower $V_{T}$, -slope or +slope. Due to the selection criteria that were chosen in order to gain a comparable number of cycles independent of the $V_{T}$ pattern and cycle class, the difference of $V_{T}$ of the preceding cycles $\Delta V_{T, \mathrm{i}+1}$ differed between $V_{T}$ patterns being significantly lower in $\mathrm{P}_{10}$ compared to $\mathrm{P}_{04}$ and $\mathrm{WN}$. Therefore, $\Delta E$ should be of lesser magnitude for $\mathrm{P}_{10}$ compared to the other patterns, if inter-tidal $\mathrm{R} / \mathrm{D}$ would be absent. However while $\Delta E$ was not significantly different from zero in patterns $\mathrm{WN}$ and P04, it was significantly negative in $\mathrm{P}_{10}$ (Figure 6), indicating the presence of inter-tidal $\mathrm{R} / \mathrm{D}$ of two or more cycles in $\mathrm{P}_{10}$. It is worth noting that this type of analysis would yield differences between -slope and +slope cycles in every viscoelastic tissue or material with relevant hysteresis independent of R/D. However the increased difference between cycle types is more likely due to a type of prolonged $\mathrm{R} / \mathrm{D}$ dynamics in agreement with (Bellardine et al., 2006), as $\mathrm{P}_{10}$ proved to be the only type of variable ventilation able to improve oxygenation. This may suggest that $\mathrm{R} / \mathrm{D}$ on a shorter time scale, which may occur during ventilation with reduced or no periodicity in tidal volume patterns, is less effective in improving lung function in this type of injury.

The reduction of the frequency $V_{T}$ pattern amplified arterial oxygenation $\mathrm{PaO}_{2}$. The possible mechanism may be stabilization 

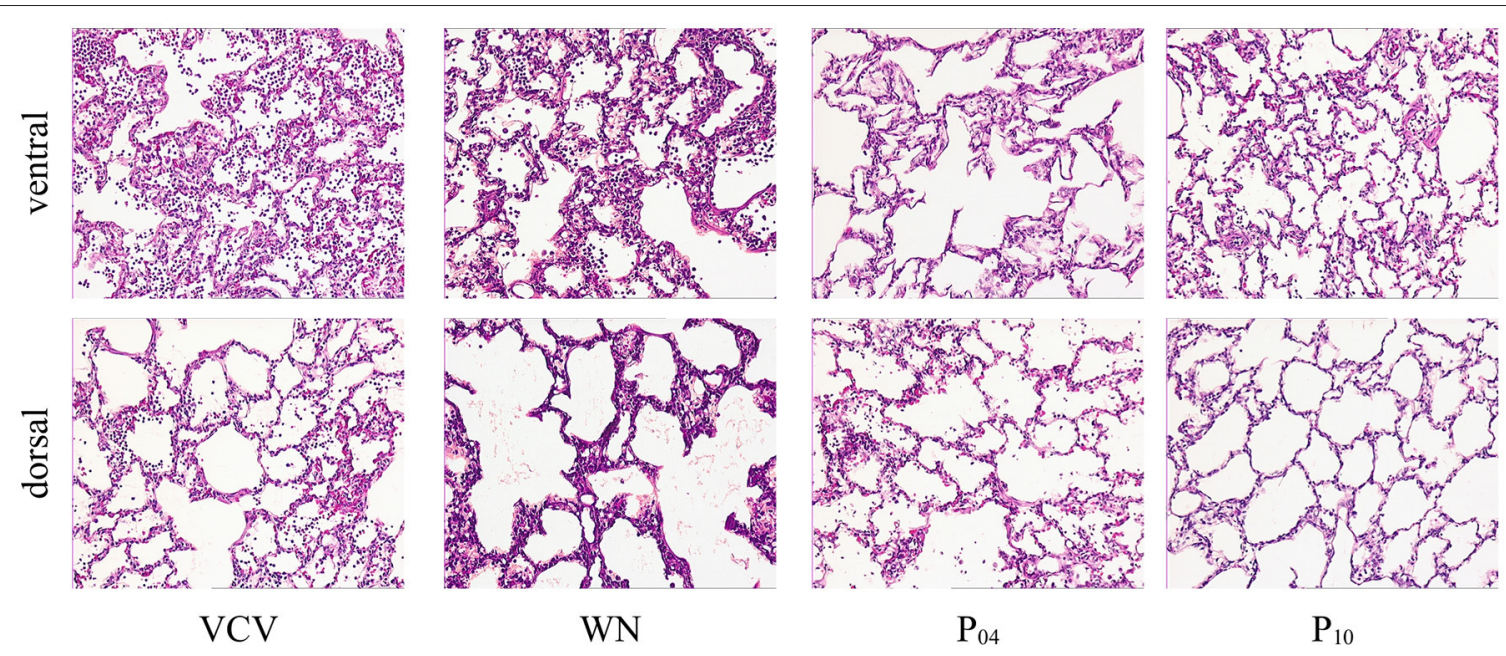

FIGURE 7 | Histological slides with HE-staining at 100-fold magnification of representative animals.

of lung recruitment by increased inter-tidal but decreased intratidal R/D. But other factors such as surfactant production/release and redistribution of perfusion may be triggered by periodic $V_{T}$ variation and may contribute additionally to improvements in lung function. However arterial oxygenation may not increase during an indefinite reduction of $V_{T}$ pattern frequency, since a $V_{T}$ frequency of zero corresponds to conventional volume controlled ventilation. If the $V_{T}$ frequency of maximal arterial oxygenation coincides with the frequency response of one participating subsystem of respiration, this frequency dependent response would be characteristic for deterministic resonance. The identification of such frequency and related subsystem were beyond the scope of this investigation. However further research on this issue would not only foster our knowledge of the respiratory system and its interactions but would facilitate further development of protective ventilation strategies.

Several mechanisms may explain the improvement of gas exchange and lung mechanics through periodic $V_{T}$ patterns. Lung recruitment can be facilitated by surfactant release due to stretch of lung epithelial type II cells. Its magnitude is related to an instantaneous $\mathrm{Ca}^{2+}$ mobilization decaying with a time constant of $9.13 \mathrm{~s}$ (Wirtz and Dobbs, 1990) and simultaneous surfactant secretion with a time constant of $19.7 \mathrm{~s}$ (Haller et al., 1998) to $94.6 \mathrm{~s}$ (Majumdar et al., 2012). Therefore, in lung areas subjected to inter-tidal R/D high $V_{T}$ cycles may activate surfactant secretion more effectively, while this surfactant is released after the strain impulse has decayed during subsequent low $V_{T}$ cycles (Edwards, 2001).

In contrast to intra-tidal, inter-tidal R/D may have beneficial effects on ventilation/perfusion matching due to redistribution of perfusion toward lung regions with improved ventilation (Sylvester et al., 2012). The transient response of local acute hypoxic pulmonary (HPV) vasoconstriction is characterized by a time constant of $151 \pm 24.8 \mathrm{~s}$ in humans (Morrell et al., 1995) and $120 \mathrm{~s}$ in dogs (Grant and Schneider, 1983). Thus, only 1.6\% of the final HPV response is reached during intra-tidal $\mathrm{R} / \mathrm{D}$ (approximately $\mathrm{T}=2 \mathrm{~s}$ ), whereas $8 \%$ is reached in regions that remain open/closed for $\sim 10 \mathrm{~s}$, which was likely achieved in $\mathrm{P}_{10}$.

The dynamics of formation and resolution of atelectasis differ according to the type of lung injury, as well as PEEP levels. In a lung lavage model in pigs, duration of atelectasis formation varied from $20.0 \pm 12.3$ to $26.5 \pm 14.0 \mathrm{~s}$, while duration of atelectasis resolution ranged from $0.8 \pm 0.6$ to $10.7 \pm 4.2 \mathrm{~s}$ (Neumann et al., 1998; Markstaller et al., 2001). This likely reduced cyclic R/D, explaining in part the benefits of the lower main frequency during variable ventilation. Possibly, a prolongation of the $V_{T}$ period up to a $T_{P}=40 \mathrm{~s}\left(\mathrm{f}_{\mathrm{P}}=0.025 \mathrm{~Hz}\right)$ might yield a further increase on oxygenation, but this claim remains speculative.

The effects of periodicity of $V_{T}$ patterns on gas exchange and lung mechanics have been investigated in one experimental and one simulation study. In pigs with oleic acid-induced lung injury, biologically and white noise, computer-generated variable ventilation led to comparable lung mechanics and gas exchange (Froehlich et al., 2008). However, the so-called Hurst exponent H, i.e. a measure of long range correlation, might not have differed relevantly between both patterns $(\mathrm{H}=0.62$ for biological noise and $\mathrm{H}=0.5$ for computer generated white noise) considering its spectrum of possible values for $\mathrm{H}=0$ anti-correlation (so-called blue noise), $\mathrm{H}=0.5$ (no correlation, white noise, respiratory rate during deep sleep) and $\mathrm{H}=1$ auto-correlation (so-called pink noise, respiratory rate during awake state; Schumann et al., 2010).

In the presented study the novelty was that we introduced a deterministic auto-correlation with a fixed frequency similar to the numerical simulation study by Ma et al. In their model, taking R/D dynamics into account, increased periodicity did not improve lung mechanics. However, different from in-vivo models, other possible factors affected by periodicity, for example surfactant release and redistribution of perfusion and ventilation were not considered in their model (Ma et al., 2011).

Although changes in the distribution of tidal ventilation did not reach statistical significance, increased homogeneity in tidal impedance images in all variability groups suggests increased 
TABLE 5 | Gene expression of markers of inflammation and cell stress.

\begin{tabular}{|c|c|c|c|c|c|}
\hline Marker & Group & $\begin{array}{l}\text { Ventral } \\
\text { region }\end{array}$ & $\begin{array}{l}\text { Group } \\
\text { effect }\end{array}$ & $\begin{array}{l}\text { Dorsal } \\
\text { region }\end{array}$ & $\begin{array}{l}\text { Group } \\
\text { effect }\end{array}$ \\
\hline \multirow[t]{4}{*}{ TNF- $\alpha$} & VCV & 1.0 & n.s. & 1.0 & n.s. \\
\hline & WN & $1.0[0.6-1.9]$ & & 0.7 [0.3-1.0] & \\
\hline & $P_{04}$ & $1.0[0.7-1.7]$ & & 0.6 [0.5-1.5] & \\
\hline & $P_{10}$ & $1.4[0.7-2.3]$ & & 0.7 [0.5-1.3] & \\
\hline \multirow[t]{4}{*}{ IL-6 } & VCV & 1.0 & n.s. & 1.0 & n.s. \\
\hline & WN & $0.9[0.6-1.2]$ & & 0.9 [0.5-1.5] & \\
\hline & $P_{04}$ & $0.9[0.2-1.3]$ & & 0.7 [0.4-1.3] & \\
\hline & $P_{10}$ & $0.8[0.3-1.4]$ & & $0.8[0.4-1.4]$ & \\
\hline \multirow[t]{4}{*}{ IL-8 } & VCV & 1.0 & n.s. & 1.0 & n.s. \\
\hline & WN & $1.5[0.8-2.1]$ & & $1.2[0.5-2.1]$ & \\
\hline & $P_{04}$ & $1.4[0.2-3.6]$ & & 0.3 [0.2-2.5] & \\
\hline & $P_{10}$ & $1.5[0.4-2.7]$ & & 0.9 [0.6-1.3] & \\
\hline \multirow[t]{4}{*}{ Amphiregulin } & VCV & 1.0 & n.s. & 1.0 & n.s. \\
\hline & WN & $0.9[0.5-1.6]$ & & 1.2 [0.5-2.2] & \\
\hline & $\mathrm{P}_{04}$ & $1.2[0.5-2.0]$ & & $0.5[0.3-1.4]$ & \\
\hline & $P_{10}$ & $1.6[0.6-3.5]$ & & 1.0 [0.7-1.5] & \\
\hline \multirow[t]{4}{*}{ Tenascin-c } & VCV & 1.0 & n.s. & 1.0 & n.s. \\
\hline & WN & $1.3[0.6-2.2]$ & & 1.0 [0.5-2.2] & \\
\hline & $\mathrm{P}_{04}$ & $1.2[0.8-2.1]$ & & $1.2[0.8-1.8]$ & \\
\hline & $P_{10}$ & $1.0[0.6-5.6]$ & & 1.6 [0.5-2.2] & \\
\hline
\end{tabular}

Gene expression of Tumor necrosis factor (TNF)- $\alpha$, Interleukin (LL)-6, Interleukin (LL)-8, Amphiregulin and Tenascin-c in ventral lung regions (ventral) and dorsal lung regions (dorsal), conventional volume controlled ventilation (VCV); variable volume controlled ventilation with Gaussian white noise pattern in tidal volume (WN); variable volume controlled ventilation with periodicity of 4 cycles $\left(P_{04}\right)$ and variable volume controlled ventilation with periodicity of 10 cycles $\left(P_{10}\right)$. Values represent $x$-fold expression of the respective gene normalized to housekeeping genes cyclophilin A and B2-microglobulin and to values of VCV animals as control group. Values are shown as median and interquartile range, and were obtained from 40 animals in total ( $n=10 /$ group). There were no missing values. Differences among groups were tested with Kruskal-Wallis test followed by Mann-Whitney U-test and Bonferroni-Holm adjustments for pairwise comparisons. n.s. (non-significant at $P<0.05)$.

lung homogeneity during variable ventilation. However, in order to avoid artifacts of the moving diaphragm, a rather cranial, cross section of the lung was addressed, and we cannot exclude the possibility that R/D occurred in the most dependent (dorsal and caudal) lung regions, contributing to the observed effects of variable ventilation on lung function.

No relevant differences among groups were found regarding lung histology, gene expression as well as protein levels of markers of inflammation in lung tissue, which is somewhat in disagreement with previous work from our own group (Spieth et al., 2009b). A possible explanation is that in the present study we used a model of severe ARDS, which might be less responsive to variable ventilation.

The improvement of oxygenation through periodic variable ventilation $\Delta \mathrm{PaO}_{2} / \mathrm{F}_{\mathrm{I}} \mathrm{O}_{2}=150 \mathrm{mmHg}$, seen in this study, compares well to other techniques as for example random variable ventilation $\Delta \mathrm{PaO}_{2} / \mathrm{F}_{\mathrm{I}} \mathrm{O}_{2}=80 \ldots 150 \mathrm{~mm} \quad \mathrm{Hg}$ (Huhle et al., 2016) and step-wise recruitment maneuvers' $\Delta \mathrm{PaO}_{2} / \mathrm{F}_{\mathrm{I}} \mathrm{O}_{2}=150 \mathrm{~mm} \mathrm{Hg}$ (Vivona et al., 2018) in the same model . In the double-hit model facilitated in this study the effects
TABLE 6 | Levels of inflammation markers in lung tissue.

\begin{tabular}{|c|c|c|c|c|c|}
\hline Marker & Group & $\begin{array}{l}\text { Ventral } \\
\text { region }\end{array}$ & $\begin{array}{l}\text { Group } \\
\text { effect }\end{array}$ & $\begin{array}{l}\text { Dorsal } \\
\text { region }\end{array}$ & $\begin{array}{l}\text { Group } \\
\text { effect }\end{array}$ \\
\hline \multirow[t]{4}{*}{ TNF- $\alpha(p g / m g)$} & VCV & $2.8[1.9-7.5]$ & n.s. & $3.0[2.4-5.8]$ & n.s. \\
\hline & WN & $2.4[0.4-4.7]$ & & $4.3[1.4-10.7]$ & \\
\hline & $\mathrm{P}_{04}$ & $3.2[1.1-4.8]$ & & $3.8[1.0-5.6]$ & \\
\hline & $P_{10}$ & $1.1[0.6-4.8]$ & & $2.9[1.1-7.4]$ & \\
\hline \multirow[t]{4}{*}{ IL-6 (pg/mg) } & VCV & $\begin{array}{c}39.5 \\
{[18.9-102.8]}\end{array}$ & n.s. & 28.2 [8.6-50.1] & n.s. \\
\hline & WN & $\begin{array}{c}31.8 \\
{[18.7-50.0]}\end{array}$ & & $34.9[13.7-106.3]$ & \\
\hline & $P_{04}$ & $\begin{array}{c}26.0 \\
{[14.4-59.2]}\end{array}$ & & $14.4[7.0-44.8]$ & \\
\hline & $P_{10}$ & $\begin{array}{c}39.1 \\
{[23.4-60.5]}\end{array}$ & & 20.4 [8.4-34.9] & \\
\hline \multirow[t]{4}{*}{ IL-8 (pg/mg) } & VCV & $\begin{array}{c}133.7 \\
{[63.1-327.5]}\end{array}$ & n.s. & $\begin{array}{c}106.1 \\
{[62.5-286.2]}\end{array}$ & n.s. \\
\hline & WN & $\begin{array}{c}118.0 \\
{[48.1-226.0]}\end{array}$ & & $\begin{array}{c}125.0 \\
{[68.8-216.4]}\end{array}$ & \\
\hline & $P_{04}$ & $\begin{array}{c}120.3 \\
{[37.5-474.1]}\end{array}$ & & $\begin{array}{c}88.75 \\
{[48.5-208.0]}\end{array}$ & \\
\hline & $P_{10}$ & $\begin{array}{c}90.6 \\
{[70.5-118.0]}\end{array}$ & & $\begin{array}{c}101.9 \\
{[72.5-130.9]}\end{array}$ & \\
\hline
\end{tabular}

Gene expression of Tumor necrosis factor (TNF)- $\alpha$, Interleukin (LL)-6, Interleukin (IL)-8, in ventral lung regions (ventral) and dorsal lung regions (dorsal), conventional volume controlled ventilation (VCV); variable volume controlled ventilation with Gaussian white noise pattern in tidal volume (WN); variable volume controlled ventilation with periodicity of 4 cycles $\left(P_{04}\right)$ and variable volume controlled ventilation with periodicity of 10 cycles $\left(P_{10}\right)$. Values are shown as median and interquartile range, and were obtained from 40 animals in total ( $n=10 /$ group). There were no missing values. However, a variable number of measurements yielded values below the detection limit of the respective ELISA kit and were excluded from the analysis. The remaining numbers of values were: in ventral regions for TNF- $\alpha$ VCV 9, WN 8, $P_{04}$ 8, P 1010 animals; for IL-6 VCV 10, WN 10, $P_{04}$ 9, $P_{10} 10$ animals; for IL-8 VCV 10, WN 10, $P_{04} 10, P_{10} 9$ animals; in dorsal regions for TNF- $\alpha$ VCV 9, WN 8, $P_{04} 8, P_{10} 10$ animals; for IL-6 VCV 8, WN 8, $P_{04}$ 9, $P_{10} 10$ animals; for IL$8 \mathrm{VCV} 10, W N$ 10, $P_{04}$ 10, $P_{10} 9$ animals. Differences among groups were tested with Kruskal-Wallis test followed by Mann-Whitney U-test and Bonferroni-Holm adjustment for pairwise comparison. n.s. (non-significant at $P<0.05$ ).

of recruitment on oxygenation might still be over-estimated compared to clinical ARDS where recruitment maneuvers' only improve oxygenation by $\Delta \mathrm{PaO}_{2} / \mathrm{F}_{\mathrm{I}} \mathrm{O}_{2}=40 \ldots 50 \mathrm{~mm} \mathrm{Hg}$ (Hodgson et al., 2011). Furthermore the full benefits of periodic variable ventilation and the relevant mechanism remain to be elucidated.

Periodic variable ventilation is straightforward implementable in experimental and conventional ventilators that are remotely controllable as e.g., the Inspira ASVp (Harvard Apparatus, Massachusetts, USA), the FlexiVent (SciReq, Montreal, Canada) and Evita XL (Draeger Medical, Luebeck, Germany).

\section{LIMITATIONS}

Our study has several limitations. First, the applied experimental model of ARDS consisted of repeated surfactant lavage (first hit) followed by consecutive ventilator induced lung injury (second hit). This model of ARDS reproduces important features of human ARDS (Matute-Bello et al., 2008), but it does not 
reflect the complex clinical picture of ARDS precluding direct extrapolation of our results to the clinical scenario. Second, the observational period was limited to $6 \mathrm{~h}$, and we cannot exclude different effects in the long term. Third, to enhance comparability between groups, we kept settings for $\mathrm{FIO}_{2}$ and PEEP constant during the observational period avoiding adjustments based on changes in gas exchange. A clinical approach including such adaptations may have produced different results. Fourth, a further prolongation of the $V_{T}$ period may have yielded different effects of periodicity on lung function in this animal model, but were not investigated. Last but not least the Gaussian distribution of the $V_{T}$ patterns used might not be tailored to the species and model of ARDS.

\section{CONCLUSIONS}

In this experimental model of severe ARDS, periodic $V_{T}$ fluctuation at a frequency of $0.05 \mathrm{~Hz}$ improved oxygenation during variable ventilation, suggesting that deterministic resonance adds further benefit to variable ventilation.

\section{DATA AVAILABILITY STATEMENT}

The datasets used and/or analyzed during the current study are available from the corresponding author on reasonable request.

\section{AUTHOR CONTRIBUTIONS}

AG and RH contributed to design the study, conducted experiments, analyzed, and interpreted all experimental data, and were major contributors in writing the manuscript. $A B$ contributed to design the study, analyzed and interpreted data on respiratory mechanics, and contributed in writing the manuscript. TK and TB conducted experiments, analyzed and

\section{REFERENCES}

Arold, S. P., Mora, R., Lutchen, K. R., Ingenito, E. P., and Suki, B. (2002). Variable tidal volume ventilation improves lung mechanics and gas exchange in a rodent model of acute lung injury. Am. J. Respir. Crit. Care Med. 165, 366-371. doi: 10.1164/ajrccm.165.3.2010155

Bates, J. H., and Irvin, C. G. (2002). Time dependence of recruitment and derecruitment in the lung: a theoretical model. J. Appl. Physiol. 93, 705-713. doi: 10.1152/japplphysiol.01274.2001

Bellardine, C. L., Hoffman, A. M., Tsai, L., Ingenito, E. P., Arold, S. P., Lutchen, K. R., et al. (2006). Comparison of variable and conventional ventilation in a sheep saline lavage lung injury model. Crit. Care Med. 34, 439-445. doi: 10.1097/01.CCM.0000196208.01682.87

Boker, A., Graham, M. R., Walley, K. R., McManus, B. M., Girling, L. G., Walker, E., et al. (2002). Improved arterial oxygenation with biologically variable or fractal ventilation using low tidal volumes in a porcine model of acute respiratory distress syndrome. Am. J. Respir. Crit. Care Med. 165, 456-462. doi: 10.1164/ajrccm.165.4.2108006

Brewster, J. F., Graham, M. R., and Mutch, W. A. C. (2005). Convexity, Jensen's inequality and benefits of noisy mechanical ventilation. J. R. Soc. Interface $R$. Soc. 2, 393-396. doi: 10.1098/rsif.2005.0043

de Magalhães, R. F., Samary, C. S., Santos, R. S., de Oliveira, M. V., Rocha, N. N., Santos, C. L., et al. (2016). Variable ventilation improves pulmonary function and reduces lung damage without increasing bacterial interpreted all experimental data, and were major contributors in writing the manuscript. IR contributed to design the study, analyzed, and interpreted data on molecular biology, and contributed in writing the manuscript. SK and NC contributed to design the study, analyze all data and write the manuscript. MK contributed to design the study, to analyze data on histologic damage, and contributed in writing the manuscript. PP contributed to design the study, analyzed and interpreted all experimental data, and was a major contributor in writing the manuscript. MA designed the study, obtained financial support, analyzed and interpreted all experimental data, and was a major contributor in writing the manuscript. All authors read and approved the final manuscript.

\section{FUNDING}

This study was funded by grant nr. GA 1256/7-1 from the Deutsche Forschungsgemeinschaft, Bonn, Germany.

\section{ACKNOWLEDGMENTS}

The authors are thankful to Susanne Henninger Abreu, research nurse, and Sabine Müller, laboratory technician, of the Pulmonary Engineering Group at the Department of Anesthesiology and Intensive Care, University Hospital Carl Gustav Carus, Technische Universität Dresden, Dresden, Germany, for their support during experiments and laboratory analyses.

\section{SUPPLEMENTARY MATERIAL}

The Supplementary Material for this article can be found online at: https://www.frontiersin.org/articles/10.3389/fphys. 2018.00905/full\#supplementary-material translocation in a rat model of experimental pneumonia. Respir. Res. 17:158. doi: 10.1186/s12931-016-0476-7

Edwards, Y. S. (2001). Stretch stimulation: its effects on alveolar type II cell function in the lung. Comp. Biochem. Physiol. A. Mol. Integr. Physiol. 129, 245-260. doi: 10.1016/S1095-6433(01)00321-X

Froehlich, K. F., Graham, M. R., Buchman, T. G., Girling, L. G., Scafetta, N., West, B. J., et al. (2008). Physiological noise versus white noise to drive a variable ventilator in a porcine model of lung injury. Can. J. Anaesth. 55, 577-586. doi: 10.1007/BF03021431

Funk, D., Graham, M. R., Girling, L., Thliveris, J., McManus, B., Walker, E., et al. (2004). A comparison of biologically variable ventilation to recruitment manoeuvres in a porcine model of acute lung injury. Respir. Res. 5:22. doi: 10.1186/1465-9921-5-22

Graham, M. R., Goertzen, A. L., Girling, L. G., Friedman, T., Pauls, R. J., Dickson, T., et al. (2011a). Quantitative computed tomography in porcine lung injury with variable versus conventional ventilation: recruitment and surfactant replacement. Crit. Care Med. 39, 1721-1730. doi: 10.1097/CCM.0b013e3182186d09

Graham, M. R., Gulati, H., Kha, L., Girling, L. G., Goertzen, A., and Mutch, W. A. (2011b). Resolution of pulmonary edema with variable mechanical ventilation in a porcine model of acute lung injury. Can. J. Anaesth. 58, 740-750. doi: 10.1007/s12630-011-9517-3

Grant, B. J., and Schneider, A. M. (1983). Dynamic response of local pulmonary blood flow to alveolar gas tensions: analysis. J. Appl. Physiol. 54, 445-452. 
Haller, T., Ortmayr, J., Friedrich, F., Völkl, H., and Dietl, P. (1998). Dynamics of surfactant release in alveolar type II cells. Proc. Natl. Acad. Sci. U.S.A. 95, 1579-1584. doi: 10.1073/pnas.95.4.1579

Hodgson, C. L., Tuxen, D. V., Davies, A. R., Bailey, M. J., Higgins, A. M., Holland, A. E., et al. (2011). A randomised controlled trial of an open lung strategy with staircase recruitment, titrated PEEP and targeted low airway pressures in patients with acute respiratory distress syndrome. Crit. Care 15:R133. doi: 10.1186/cc10249

Huhle, R., Pelosi, P., and de Abreu, M. G. (2016). Variable ventilation from bench to bedside. Crit. Care 20:62. doi: 10.1186/s13054-0161216-6

Kano, S., Lanteri, C. J., Duncan, A. W., and Sly, P. D. (1994). Influence of nonlinearities on estimates of respiratory mechanics using multilinear regression analysis. J. Appl. Physiol. 77, 1185-1197.

Kiss, T., Silva, P. L., Huhle, R., Moraes, L., Santos, R. S., Felix, N. S., et al. (2016). Comparison of different degrees of variability in tidal volume to prevent deterioration of respiratory system elastance in experimental acute lung inflammation. Br. J. Anaesth. 116, 708-715. doi: 10.1093/bja/aew093

Lefevre, G. R., Kowalski, S. E., Girling, L. G., Thiessen, D. B., and Mutch, W. A. (1996). Improved arterial oxygenation after oleic acid lung injury in the pig using a computer-controlled mechanical ventilator. Am. J. Respir. Crit. Care Med. 154, 1567-1572. doi: 10.1164/ajrccm.154.5.8912782

Ma, B., Suki, B., and Bates, J. H. (2011). Effects of recruitment/derecruitment dynamics on the efficacy of variable ventilation. J. Appl. Physiol. 110, 1319-1326. doi: 10.1152/japplphysiol.01364.2010

Majumdar, A., Arold, S. P., Bartolák-Suki, E., Parameswaran, H., and Suki, B. (2012). Jamming dynamics of stretch-induced surfactant release by alveolar type II cells. J. Appl. Physiol. 112, 824-831. doi: 10.1152/japplphysiol.00975.2010

Markstaller, K., Eberle, B., Kauczor, H.-U., Scholz, A., Bink, A., Thelen, M., et al. (2001). Temporal dynamics of lung aeration determined by dynamic CT in a porcine model of ARDS. Br. J. Anaesth. 87, 459-468. doi: 10.1093/bja/8 7.3.459

Massa, C. B., Allen, G. B., and Bates, J. H. (2008). Modeling the dynamics of recruitment and derecruitment in mice with acute lung injury. J. Appl. Physiol. 105, 1813-1821. doi: 10.1152/japplphysiol.90806.2008

Matute-Bello, G., Frevert, C. W., and Martin, T. R. (2008). Animal models of acute lung injury. Am. J. Physiol. Lung Cell. Mol. Physiol. 295, L379-L399. doi: 10.1152/ajplung.00010.2008

Morrell, N. W., Nijran, K. S., Biggs, T., and Seed, W. A. (1995). Magnitude and time course of acute hypoxic pulmonary vasoconstriction in man. Respir. Physiol. $100,271-281$.

Mutch, W. A. C., Graham, M. R., Girling, L. G., and Brewster, J. F. (2005). Fractal ventilation enhances respiratory sinus arrhythmia. Respir. Res. 6:41. doi: 10.1186/1465-9921-6-41

Mutch, W. A., Harms, S., Lefevre, G. R., Graham, M. R., Girling, L. G., and Kowalski, S. E. (2000). Biologically variable ventilation increases arterial oxygenation over that seen with positive end-expiratory pressure alone in a porcine model of acute respiratory distress syndrome. Crit. Care Med. 28, 2457-2464. doi: 10.1097/00003246-200007000-00045

Neumann, P., Berglund, J. E., Fernández Mondéjar, E., Magnusson, A., and Hedenstierna, G. (1998). Dynamics of lung collapse and recruitment during prolonged breathing in porcine lung injury. J. Appl. Physiol. 85, 1533-1543. doi: 10.1152/jappl.1998.85.4.1533

R Core Team (2016). R: A Language and Environment for Statistical Computing. Vienna: R Foundation for Statistical Computing. Available online at: http:// www.R-project.org/
Samary, C. S., Moraes, L., Santos, C. L., Huhle, R., Santos, R. S., Ornellas, D. S., et al. (2016). Lung functional and biologic responses to variable ventilation in experimental pulmonary and extrapulmonary acute respiratory distress syndrome. Crit. Care Med. 44:e553-62. doi: 10.1097/CCM.0000000000001611

Schumann, A. Y., Bartsch, R. P., Penzel, T., Ivanov, P. C., and Kantelhardt, J. W. (2010). Aging effects on cardiac and respiratory dynamics in healthy subjects across sleep stages. Sleep 33, 943-955. doi: 10.1093/sleep/33.7.943

Silva, P. L., Güldner, A., Uhlig, C., Carvalho, N., Beda, A., Rentzsch, I., et al. (2013). Effects of intravascular volume replacement on lung and kidney function and damage in nonseptic experimental lung injury. Anesthesiology 118, 395-408. doi: 10.1097/ALN.0b013e31827e554c

Spieth, P. M., Carvalho, A. R., Güldner, A., Pelosi, P., Kirichuk, O., Koch, T., et al. (2009a). Effects of different levels of pressure support variability in experimental lung injury. Anesthesiology 110, 342-350. doi: 10.1097/ALN.0b013e318194d06e

Spieth, P. M., Carvalho, A. R., Pelosi, P., Hoehn, C., Meissner, C., Kasper, M., et al. (2009b). Variable tidal volumes improve lung protective ventilation strategies in experimental lung injury. Am. J. Respir. Crit. Care Med. 179, 684-693. doi: 10.1164/rccm.200806-975OC

Spieth, P. M., Knels, L., Kasper, M., Domingues Quelhas, A., Wiedemann, B., Lupp, A., et al. (2007). Effects of vaporized perfluorohexane and partial liquid ventilation on regional distribution of alveolar damage in experimental lung injury. Intensive Care Med. 33, 308-314. doi: 10.1007/s00134-006-0428-7

Suki, B., Alencar, A. M., Sujeer, M. K., Lutchen, K. R., Collins, J. J., Andrade, J. S. Jr., et al. (1998). Life-support system benefits from noise. Nature 393, 127-128.

Sylvester, J. T., Shimoda, L. A., Aaronson, P. I., and Ward, J. P. T. (2012). Hypoxic pulmonary vasoconstriction. Physiol. Rev. 92, 367-520. doi: 10.1152/physrev.00041.2010

Thammanomai, A., Hamakawa, H., Bartolák-Suki, E., and Suki, B. (2013). Combined effects of ventilation mode and positive end-expiratory pressure on mechanics, gas exchange and the epithelium in mice with acute lung injury. PloS ONE 8:e53934. doi: 10.1371/journal.pone.0053934

Thammanomai, A., Hueser, L. E., Majumdar, A., Bartolák-Suki, E., and Suki, B. (2008). Design of a new variable-ventilation method optimized for lung recruitment in mice. J. Appl. Physiol. 104, 1329-1340. doi: 10.1152/japplphysiol.01002.2007

Vivona, L., Braune, A., Bluth, T., Kiss, T., Kircher, M., Boszak, C., et al. (2018). Variable ventilation is superior to conventional recruitment for reversal of atelectasis in anesthetized pigs. Am. J. Resp. Crit. Care Med. 197:A5122.

Wirtz, H. R., and Dobbs, L. G. (1990). Calcium mobilization and exocytosis after one mechanical stretch of lung epithelial cells. Science 250, 1266-1269. doi: $10.1126 /$ science. 2173861

Conflict of Interest Statement: MA has been granted patents on variable pressure support ventilation, which were licensed to Dräger Medical AG, Lübeck, Germany.

The remaining authors declare that the research was conducted in the absence of any commercial or financial relationships that could be construed as a potential conflict of interest.

Copyright (C) 2018 Güldner, Huhle, Beda, Kiss, Bluth, Rentzsch, Kerber, Carvalho, Kasper, Pelosi and de Abreu. This is an open-access article distributed under the terms of the Creative Commons Attribution License (CC BY). The use, distribution or reproduction in other forums is permitted, provided the original author(s) and the copyright owner(s) are credited and that the original publication in this journal is cited, in accordance with accepted academic practice. No use, distribution or reproduction is permitted which does not comply with these terms. 